\title{
NGHIÊN CÚU CÁC YẾU TỐ ẢNH HƯởNG ĐẾN HỆ SỐ AN TOÀN VỐN TẠI CÁC NGÂN HÀNG THƯƠNG MẠI VIÊTT NAM ĐƯợC NGÂN HÀNG NHÀ NƯỚC CHỈ ĐỊNH THÍ ĐIỂM THỤ̉C HIỆN BASEL II
}

\author{
NGUYẼ̃N KIM CHI \\ Trường Đại học Công nghiệp thành phố Hồ Chi Minh; \\ nguyenkimchi@iuh.edu.vn
}

Tóm tắt. Mục tiêu của bài viết này là nghiên cứu các yếu tố ảnh hưởng đến hệ số an toàn vốn tại 10 NHTM Việt Nam được Ngân hàng Nhà nước Việt Nam (NHNN) chỉ định thí điểm thực hiện theo tiêu chuẩn Basel II bắt đầu từ tháng 2/2016. Bài viết sử dụng mẫu 10 NHTM Việt Nam bao gồm: Vietcombank, BIDV, VietinBank, Techcombank, ACB, VPBank, MBB, MaritimeBank, Sacombank và VIB, được nghiên cứu trong giai đoạn từ năm 2007 đến 2016 thông qua phương pháp FGLS (Feasible Generalized Least Square). Kết quả cho thấy quy mô ngân hàng, khả năng sinh lời trên tổng tài sản, tính thanh khoản và số tiền gửi của khách hàng có tác động âm lên hệ số an toàn vốn của ngân hàng. Trong khi đó, hệ số đòn bẩy có tác động dương lên hệ số an toàn vốn của ngân hàng. Dự phòng cho vay khó đòi và số tiền cho vay tác động không có ý nghĩa lên hệ số an toàn vốn của ngân hàng.

Từ khóa. Hệ số an toàn vốn, ngân hàng thương mại, FGLS

\section{RESEARCHING FACTORS AFFECTING TO CAPITAL ADEQUACY RATIO OF 10 VIETNAM JOINT - STOCK COMMERCIAL BANKS APPOINTED TO EXECUTE ACCORDING TO STANDARD BASEL II BY VIETNAM STATE BANK}

\begin{abstract}
The purpose of this study is to research about influential factors affecting to capital adequacy ratio of 10 Vietnam Joint-stock Commercial banks appointed to execute according to Standard Basel II by Vietnam State Bank, from 02/2016. The study uses samples from 10 Vietnam Joint-stock Commercial banks including: Vietcombank, BIDV, VietinBank, Techcombank, ACB, VPBank, MBB, MaritimeBank, Sacombank and VIB, researched during the periods of 2007 to 2016 using FGLS method (Feasible Generalized Least Square). The results indicated that while bank size, return on assets, liquidity and deposits had negative impacts on capital adequacy ratio, the leverage had positive influences on it. On the other hand, loan loss reserves and loans were found no significant effect on capital adequacy ratio.
\end{abstract}

Keywords. Capital adequacy ratio, commercial bank, FGLS

\section{GIỚI THIẾU}

Năm 1988, BCBS (Ủy ban Basel về giám sát ngân hàng) đã giới thiệu một khung rủi ro tín dụng (Basel I) xác định các tiêu chuẩn về vốn để hạn chế rủi ro kinh doanh của các ngân hàng và tăng cường hệ thống tài chính. Để đáp ứng các yêu cầu của phát triển liên tục trong ngành ngân hàng, các quy định này đã được sửa đổi và vào tháng 6 năm 2004, một hiệp ước về vốn mới (Basel II) được ban hành. Hiệp ước vốn Basel II nhằm nâng cao mức độ an toàn, hiệu quả, lành mạnh và năng lực cạnh tranh của hệ thống ngân hàng. Hầu hết các nước trong khu vực đều đã áp dụng chuẩn này, nhưng Việt Nam mới chỉ có 1 trường hợp Ngân hàng Phương Đông công bố áp dụng thành công vào tháng 12/2017. Việc áp dụng tiêu chuẩn Basel II vì vậy là một xu thế tất yếu và bắt buộc khi Việt Nam đang hội nhập sâu rộng với khu vực và trên thế giới. Định hướng thực hiện Basel II trong hệ thống ngân hàng đã được NHNN xác định là một trong những nhiệm vụ trọng tâm của ngành ngân hàng. Cụ thể, NHNN đã có Công văn số 1601/NHNN-TTGSNH ngày 17/3/2014 lựa chọn 10 ngân hàng trong nước thí điểm triển khai Basel II, tiến tới thực hiện triển khai áp dụng Basel II đối với tất cả các ngân hàng trong nước. NHNN đã xây dựng và ban hành Thông tư 41/2016/TT-NHNN ngày 30/12/2016 quy định tỷ lệ an toàn vốn đối với ngân hàng, chi nhánh NHNN theo phương pháp tiêu chuẩn và có hiệu lực thi hành từ $1 / 1 / 2020$ đối với toàn hệ thống ngân hàng.

Trong thời gian qua, 10 ngân hàng trong nước thí điểm triển khai Basel II đã hoàn thành các khâu đánh giá toàn diện về quy trình, chính sách, cơ sở dữ liệu... cho các loại rủi ro. Các trụ cột chính khác của Basel II 
về vốn tối thiểu, cách thức công bố thông tin cũng đang từng bước hoàn thiện. Hệ số an toàn vốn là một trong nhưng tiêu chí quan trọng khi các ngân hàng tiếp cận với chuẩn Basel II. Đây là một trong các chỉ tiêu rất quan trọng trong việc đảm bảo an toàn trong hoạt động của các NHTM. Tỉ lệ này thường được dùng để bảo vệ những người gửi tiền trước rủi ro của ngân hàng và tăng tính ổn định cũng như hiệu quả của hệ thống tài chính toàn cầu. Hay nói cách khác, khi ngân hàng đảm bảo được tỉ lệ này tức là nó đã tự tạo ra một tấm đệm chống lại những cú sốc về tài chính, vừa tự bảo vệ mình, vừa bảo vệ những người gửi tiền. Do đó, thời điểm mà 10 NHTM đang từng bước triển khai áp dụng Basel II thì việc nâng cao hệ số an toàn vốn trên cơ sở đảm bảo an toàn trong hoạt động của hệ thống NHTM là vô cùng cấp thiết. Để có thể thực hiện được mục tiêu trên cần xác định rõ những yếu tố nào ảnh hưởng đến hệ số an toàn vốn tại các NHTM này. Chính vì vậy, mục tiêu nghiên cứu của bài viết này là xác định các yếu tố ảnh hưởng đến hệ số an toàn vốn tại tại 10 NHTM Việt Nam được NHNN chỉ định thí điểm thực hiện theo tiêu chuẩn Basel II.

Bài báo sử dụng dữ liệu bảng bao gồm 10 NHTM Việt Nam trong giai đoạn từ năm 2007 đến 2016, ước tính bằng phương pháp FGLS để có thể xử lý tốt hiện tượng phương sai thay đổi của mô hình.Please follow the steps outlined below when submitting your manuscript to the Journal of Science and Technology. This style guide now has several important modifications, so all authors should read this new version.

\section{CÁC NGHIÊN CÚU THỰC NGHIỆM TRƯớC ĐÂY VỀ CÁC YẾU TỐ ẢNH HƯởNG ĐÉN HÊ SỐ AN TOÀN VỐN TẠI NGẦN HÀNG}

\begin{tabular}{|c|c|c|}
\hline Tác giả & Phương pháp và mẫu nghiên cứu & Kết quả nghiên cứu \\
\hline $\begin{array}{l}\text { Ijaz Hussain } \\
\text { Bokhari và Syed } \\
\text { Muhamad Ali } \\
(2009)\end{array}$ & $\begin{array}{l}\text { Nghiên cứu sử dụng phương pháp hồi quy } \\
\text { OLS thông thường, các phân tích thống kê } \\
\text { mô tả được tiến hành đề đo lường các yếu } \\
\text { tố quyết định đến CAR tại các NHTM ở } \\
\text { Pakistan với số liệu lấy từ } 12 \text { NHTM giai } \\
\text { đoạn 2005-2009 }\end{array}$ & $\begin{array}{l}\text { Kết quả cho thấy có mối tương quan } \\
\text { mạnh giữa tiền gửi, lợi nhuận trên vốn } \\
\text { chủ sở hữu, danh mục đầu tư rủi ro với } \\
\text { CAR. }\end{array}$ \\
\hline $\begin{array}{l}\text { Farah } \\
\text { Margaretha và } \\
\text { Diana } \\
\text { Setiyaningrum } \\
\text { (2011) }\end{array}$ & $\begin{array}{l}\text { Phương pháp phân tích dữ liệu được sử } \\
\text { dụng trong nghiên cứu này hồi quy OLS } \\
\text { thông thường và hồi quy cố định tác động } \\
\text { (Fix effects). Nghiên cứu lây mấu là các } \\
\text { NHTM niêm yết trên Sở giao dịch chứng } \\
\text { khoán Indonesia và có báo cáo tài chính } \\
\text { trong thời gian từ } 2003-2008 \text {. }\end{array}$ & $\begin{array}{l}\text { Kết quả nghiên cứu chỉ ra rằng chỉ số } \\
\text { đánh giá rủi ro, tỷ lệ thu nhập lãi cận } \\
\text { biên ròng và hệ số giữa tài sản ngằn } \\
\text { hạn trên tổng tiền gửi của khách hàng } \\
\text { có một ảnh hưởng tiêu cực và đáng kể } \\
\text { lên CAR. Trách nhiệm thanh khoản } \\
\text { nhìn thấy từ vốn chủ sở hữu/tổng nọ } \\
\text { phải trả có một ảnh hưởng tích cực và } \\
\text { quan trọng đến CAR }\end{array}$ \\
\hline $\begin{array}{l}\text { Ahmet } \\
\text { Büyüksalvarc11 } \\
\text { and Hasan } \\
\text { Abdioğlu2 } \\
\text { (2011) }\end{array}$ & $\begin{array}{l}\text { Nghiên cứu sử dụng dữ liệu bảng và } \\
\text { phương pháp hồi quy OLS thông thường. } \\
\text { Nghiên cứu này với mục đích là tìm ra các } \\
\text { yếu tố quyết định đến CAR của các NHTM } \\
\text { Thổ Nhĩ Kỳ giai đoạn } 2006 \text { - } 2010\end{array}$ & $\begin{array}{l}\text { Nghiên cứu chỉ ra rằng trong số các } \\
\text { biến độc lập chỉ có hệ số cho vay, lợi } \\
\text { nhuận trên vốn chủ sở hữu và hệ sồ đòn } \\
\text { bây có tác động âm lên CAR trong khi } \\
\text { đó dự phòng khoản cho vay khó đòi và } \\
\text { lợi nhuận trên tổng tài sản tác động } \\
\text { dương. Các biến còn lại không có ý } \\
\text { nghĩa về mặt thống kê. }\end{array}$ \\
\hline $\begin{array}{l}\text { Mohammed T. } \\
\text { Abusharba, } \\
\text { Iwan } \\
\text { Triyuwono, } \\
\text { Munawar Ismail } \\
\text { và Aulia F. } \\
\text { Rahman (2012) }\end{array}$ & $\begin{array}{l}\text { Nghiên cứu sử dụng dữ liệu bảng và } \\
\text { phương pháp hồi quy OLS thông thường. } \\
\text { Nghiên cứu về hệ số an toàn vôn của các } \\
\text { Ngân hàng Hồi giáo ở Indonesia giai đoạn } \\
2009 \text { - } 2011\end{array}$ & $\begin{array}{l}\text { Kết quả nghiên cứu chỉ ra rằng là lợi } \\
\text { nhuận trên tồng tài sản và tỷ lệ tồng số } \\
\text { tiền ngân hàng cho vay trên tổng số } \\
\text { tiền gựi của khách hàng tại ngân hàng } \\
\text { có mối tương quan dương và đáng kể } \\
\text { lên CAR. Tỷ lệ nợ xấu có mối tương } \\
\text { quan âm với CAR. Các biến còn lại } \\
\text { không có ý nghĩa về mặt thống kê }\end{array}$ \\
\hline
\end{tabular}




\section{PHƯƠNG PHÁP NGHIÊN CÚU}

\subsection{Mô hình nghiên cứu}

Mô hình nghiên cứu cho điều kiện thực tế của Việt Nam dựa trên mô hình nghiên cứu của Thổ Nhĩ Kỳ làm nền tảng và có thay đổi cho phù hợp như sau:

CARit $=\alpha+\beta 1$ SIZEit $+\beta 2$ LEVit $+\beta 3$ LLRit $+\beta 4$ DEPit $+\beta 5$ LOAit $+\beta 6$ LIQit $+\beta 7$ ROAit $+\varepsilon$ it

Trong đó:

CARit là hệ số an toàn vốn của ngân hàng i tại thời điểm $\mathrm{t}$

(SIZE)it là quy mô ngân hàng $i$ tại thời điểm $\mathrm{t}$, được lượng hóa bằng tổng tài sản ngân hàng $\mathrm{i}$ tại thời điểm $\mathrm{t}$.

(DEP)it là khoản tiền gửi của khách hàng tại ngân hàng $i$ tại thời điểm $\mathrm{t}$, được lượng hóa bằng tổng tiền gửi của khách hàng tại ngân hàng $i$ trong năm $t$ chia cho tổng tài sản của ngân hàng $i$ trong năm $t$.

(LOA)it là khoản tiền cho vay của ngân hàng $i$ tại thời điểm $t$, được lượng hóa bằng tiền cho vay của ngân hàng $i$ trong năm $t$ chia cho tổng tài sản của ngân hàng $i$ trong năm $t$.

(LLR)it là rủi ro tín dụng của ngân hàng $\mathrm{i}$ tại thời điểm $\mathrm{t}$, được lượng hóa bằng dự phòng tổn thất rủi ro tín dụng của ngân hàng i trong năm $t$ chia cho tổng dư nợ tín dụng tại ngân hàng i trong năm $t$.

(LIQ)it là hệ số thanh khoản của ngân hàng $i$ tại thời điểm $t$, được lượng hóa bằng tiền mặt và các khoản tương đương tiền của ngân hàng $i$ trong năm $t$ chia cho tổng tài sản của ngân hàng $i$ trong năm $t$.

(ROA)it là khả năng sinh lời của ngân hàng $i$ tại thời điểm $t$, được lượng hóa bằng lợi nhuận trước thuế của ngân hàng $\mathrm{i}$ trong năm $\mathrm{t}$ chia cho tổng tài sản của ngân hàng $\mathrm{i}$ trong năm $\mathrm{t}$.

(LEV)it là hệ số đòn bẩy tài chính được lượng hóa bằng vốn chủ sở hữu của ngân hàng $\mathrm{i}$ trong năm $\mathrm{t}$ chia cho tổng tài sản của ngân hàng $i$ trong năm $t$.

Bảng 1: Mô tả các biến được sử dụng trong mô hình hồi quy

\begin{tabular}{|l|l|l|l|}
\hline Biến & Mô tả & Ký hiệu & Dấu kỳ vọng \\
\hline Hệ số an toàn vốn & Hệ số an toàn vốn của ngân hàng tại thời điểm t. & CAR & \\
\hline Quy mô ngân hàng & Tống tài sản của ngân hàng & SIZE & $+/-$ \\
\hline Hệ số đòn bẩy tài chính & Vốn chủ sở hữu/ Tồng tài sản & LEV & $+/-$ \\
\hline $\begin{array}{l}\text { Dự phòng các khoản cho vay } \\
\text { khó đòi }\end{array}$ & $\begin{array}{l}\text { Dự phòng tổn thất rủi ro tín dụng/ Tổng dư nợ tín } \\
\text { dụng }\end{array}$ & LLR & - \\
\hline Tiền gửi của khách hàng & Tổng tiền gửi của khách hàng/ Tổng tài sản & DEP & + \\
\hline Tiền cho vay của NH & Tổng số tiền cho vay/ Tổng tài sản & LOA & + \\
\hline Hệ số thanh khoản & $\begin{array}{l}\text { Tiền mặt và các khoản tương đương tiền/ Tổng tài } \\
\text { sản }\end{array}$ & LIQ & + \\
\hline Khả năng sinh lợi & Lợi nhuận trước thuế/ Tổng tài sản & ROA & $+/-$ \\
\hline
\end{tabular}

\subsection{Phương pháp nghiên cứu}

Để đo lường mối quan hệ giữa CAR với các yếu tố như quy mô ngân hàng, các khoản tiền gửi, các khoản cho vay, dự phòng rủi ro ro tín dụng, khả năng thanh khoản, khả năng sinh lời và hệ số đòn bẩy, sử dụng phương pháp phân tích dữ liệu bảng (panel data) với phương pháp FGLS. Phương pháp FGLS sẽ ước tính mô hình theo phương pháp OLS (ngay cả trong trường hợp có sự tồn tại của hiện tượng tự tương quan và phương sai thay đổi). Các sai số được rút ra từ mô hình sẽ được dùng để ước tính ma trận phương sai - hiệp phương sai của sai số. Cuối cùng, sử dụng ma trận này để chuyển đổi các biến ban đầu và ước tính giá trị các tham số cần tìm trong trong mô hình.

\subsection{Dữ liệu nghiên cứu}

\subsubsection{Mẫu nghiên cưu}

Bài báo nghiên cứu trong phạm vi 10 NHTM Việt Nam được NHNN chỉ định thí điểm thực hiện theo tiêu chuẩn Basel II bắt đầu từ tháng 2/2016, bao gồm: Vietcombank, BIDV, VietinBank, Techcombank, ACB, VPBank, MBB, MaritimeBank, Sacombank và VIB. Tác giả sử dụng dữ liệu bảng của 10 NHTM Việt Nam trên trong khoảng thời gian từ năm 2007 đến năm 2016.

\subsubsection{Nguồn dũ liệu nghiên cưu}

Dữ liệu được thu thập từ các báo cáo thường niên, báo cáo tài chính của 10 NHTM Việt Nam trên website của các ngân hàng trong khoảng thời gian từ năm 2007 đến năm 2016. 


\section{KÊT QUẢ NGHIÊN CÚU}

\subsection{Thống kê mô tả (Bảng 2)}

Giá trị trung bình CAR của 10 NHTM Việt Nam đang nghiên cứu là 0.125445 (12.54\%), giá trị lớn nhất là $0.266500(26.65 \%)$ và giá trị nhỏ nhất là $0.066700(6.67 \%)$. Theo quy định của Thông tư 13/2010/TTNHNN, CAR của các ngân hàng phải đạt tối thiểu $9 \%$ và trong báo cáo tổng quan thị trường tài chính năm 2016 của Ủy Ban giám sát tài chính Quốc gia, CAR của toàn hệ thống ước tính 2016 là 11,3\% (năm 2015 là $11,6 \%$ ), toàn hệ thống có 4/92 NHTM có CAR dưới $9 \%$. Như vậy, giá trị trung bình CAR của khối các ngân hàng này vượt so với mức quy định của $\mathrm{NHNN}$ và so với trung bình toàn ngành. Tuy nhiên kể từ tháng 2/2016 khi khối các ngân hàng này chính thức áp dụng tiêu chuẩn an toàn vốn theo Basel II cho thấy CAR giảm mạnh so với số báo cáo hiện tại, chủ yếu do tài sản có quy đổi rủi ro tăng. Theo tính toán nếu áp dụng Basel II thì CAR giảm xuống dưới 8\%. Vì vậy quy định trong Thông tư 41/2016/TT-NHNN giảm tỷ lệ an toàn vốn tối thiểu từ mức $9 \%$ xuống mức $8 \%$ của NHNN là nhằm mở đường cho việc áp dụng chuẩn Basel II vào hệ thống các ngân hàng. Việc đảm bảo CAR tối thiểu sẽ là một trong những thách thức không nhỏ đối với nhóm các ngân hàng này. Xác định các yếu tố ảnh hưởng đến CAR trong bài nghiên cứu sẽ giúp các nhà quản lý ngân hàng định hướng các giải pháp trong việc đảm bảo an toàn trong hoạt động của ngân hàng.

Bảng 2: Thống kê mô tả các biến trong mô hình nghiên cứu

\begin{tabular}{|c|c|c|c|c|c|}
\hline Biến & $\begin{array}{c}\text { Số quan } \\
\text { sát }\end{array}$ & $\begin{array}{c}\text { Giá trị trung } \\
\text { bình }\end{array}$ & $\begin{array}{c}\text { Độ lệch } \\
\text { chuẩn }\end{array}$ & Giá trị nhỏ nhất & Giá trị lớn nhất \\
\hline CAR & 100 & 0.125445 & 0.036163 & 0.066700 & 0.266500 \\
\hline LEV & 100 & 0.078102 & 0.022454 & 0.065402 & 0.146859 \\
\hline LLR & 100 & 0.011739 & 0.007240 & 0.000158 & 0.031859 \\
\hline DEP & 100 & 0.636000 & 0.126340 & 0.060029 & 0.892170 \\
\hline LOA & 100 & 0.513455 & 0.127357 & 0.220052 & 0.731175 \\
\hline LIQ & 100 & 0.018513 & 0.020686 & 0.004916 & 0.123594 \\
\hline ROA & 100 & 0.012713 & 0.005858 & 0.000469 & 0.027342 \\
\hline SIZE & 100 & $2.32 \mathrm{E}+14$ & $2.13 \mathrm{E}+14$ & $1.76 \mathrm{E}+13$ & $1.01 \mathrm{E}+15$ \\
\hline
\end{tabular}

Nguồn: Tổng hợp của tác giả từ dữ liệu nghiên cứu dựa trên phần mềm Stata

Bảng 3: Ma trận tương quan giữa các biến trong mô hình nghiên cứu

\begin{tabular}{|l|l|l|l|l|l|l|l|l|}
\hline & CAR & SIZE & LEV & LLR & DEP & LOA & LIQ & ROA \\
\hline CAR & $\mathbf{1 . 0 0}$ & -0.39 & 0.59 & 0.03 & -0.31 & -0.33 & -0.07 & -0.18 \\
\hline SIZE & -0.39 & $\mathbf{1 . 0 0}$ & -0.39 & 0.06 & 0.24 & 0.54 & -0.22 & -0.17 \\
\hline LEV & 0.59 & -0.39 & $\mathbf{1 . 0 0}$ & 0.13 & -0.03 & -0.15 & 0.21 & 0.01 \\
\hline LLR & 0.03 & 0.06 & 0.13 & $\mathbf{1 . 0 0}$ & 0.06 & -0.16 & -0.37 & -0.24 \\
\hline DEP & -0.31 & 0.24 & -0.03 & 0.06 & $\mathbf{1 . 0 0}$ & 0.54 & -0.02 & -0.07 \\
\hline LOA & -0.33 & 0.54 & -0.15 & -0.16 & 0.54 & $\mathbf{1 . 0 0}$ & -0.08 & -0.06 \\
\hline LIQ & -0.07 & -0.22 & 0.21 & -0.37 & -0.02 & -0.08 & $\mathbf{1 . 0 0}$ & 0.33 \\
\hline ROA & -0.18 & -0.17 & 0.01 & -0.24 & -0.07 & -0.06 & 0.33 & $\mathbf{1 . 0 0}$ \\
\hline
\end{tabular}

Nguồn: Kết quả dựa trên tính toán từ dữ liệu nghiên cứu với phần mềm Stata Bảng 4: Hệ số phóng đại (VIF) của các biến trong mô hình nghiên cứu

\begin{tabular}{|c|c|c|c|c|c|c|c|c|c|}
\hline Biến & CAR & SIZE & LEV & LLR & DEP & LOA & LIQ & ROA & Mean VIF \\
\hline VIF & 5.72 & 5.19 & 2.07 & 1.58 & 1.54 & 1.53 & 1.48 & 1.17 & 2.53 \\
\hline
\end{tabular}

Nguồn: Kết quả dựa trên tính toán từ dữ liệu nghiên cứu với phần mềm Stata Hệ số tương quan giữa CAR với SIZE (-0.39), DEP (-0.31), LOA (-0.33), LIQ (-0.07), ROA (-0.18) là âm cho thấy mối tương quan nghịch chiều giữa $\mathrm{CAR}$ với các biến này. Trong khi đó hệ số tương quan giữa CAR với $L E V(0.59)$ và $L L R(0.03)$ cho thấy mối tương quan thuận chiều giữa CAR với các biến này (Bảng $3)$. Có thể nhận thấy các cặp biến trong mô hình đều có hệ số tương quan tuyến tính nhỏ hơn 0.8 . Hệ số phóng đại VIF của các biến đều nhỏ hơn 10 và giá trị VIF trung bình bằng 2.53 (Bảng 4). Vì vậy dữ liệu nghiên cứu không xuất hiện hiện tượng đa cộng tuyến nghiêm trọng.

Tiếp theo, để kiểm tra liệu có sự tồn tại của hiện tượng phương sai thay đổi hay không, tác giả sử dụng kiểm định Breusch-Pagan / Cook-Weisberg kết quả cho thấy giả thuyết H0 bị bác bỏ $(\chi 2(1)=12.61$, Pvalue $=0.0004)($ Phụ lục 4$)$ tức là tồn tại hiện tượng phương sai thay đổi trong mô hình. Ngoài ra, kiểm tra 
sự tự tương quan trong mô hình và nhận thấy giả thuyết $\mathrm{H} 0$ bị bác bỏ nghĩa là tồn tại hiện tượng tự tương quan trong mô hình $(\mathrm{F}(1,9)=13.066, \mathrm{P}$-value = 0.00056) (Phụ lục 5). Do tồn tại hiện tượng phương sai thay đổi và tự tương quan, tác giả sử dụng phương pháp FGLS để khắc phục hiện tượng này trong mô hình. Việc sử dụng phương pháp phân tích dữ liệu theo panel data và FGLS sẽ tái cấu trúc lại mô hình, theo đó, các biến được đưa vào mô hình có thể được xem là khá phù hợp trong việc xem xét các yếu tố tác động đến CAR tại các NHTM Việt Nam đang nghiên cứu.

\subsection{Kết quả nghiên cứu}

Bài nghiên cứu sử dụng phương pháp FGLS để xác định các yếu tố ảnh hưởng đến CAR tại các NHTM Việt Nam đang nghiên cứu. Kết quả ước tính các yếu tố ảnh hưởng đến CAR theo FGLS được tổng hợp sau khi tiến hành chạy xong các mô hình bằng phần mềm thống kê chuyên dụng Stata 13. (Bảng 5)

Bảng 5: Kết quả ước tính các yếu tố ảnh hưởng đến CAR theo phương pháp FGLS

\begin{tabular}{|l|l|l|l|}
\hline Biến độc lập & Hệ số $\beta$ & Giá trị t & p-value \\
\hline SIZE & $-3.11 \mathrm{E}-17$ & -2.61 & $0.009^{*}$ \\
\hline LEV & 0.911254 & 8.43 & $0.000^{*}$ \\
\hline LLR & -0.560561 & -1.53 & 0.126 \\
\hline DEP & -0.070294 & -4.15 & $0.000^{*}$ \\
\hline LOA & -0.002690 & -0.11 & 0.910 \\
\hline LIQ & -0.412457 & -3.3 & $0.001^{*}$ \\
\hline ROA & -1.395236 & -3.61 & $0.000^{*}$ \\
\hline Constant & 0.140529 & 8.64 & $0.000^{*}$ \\
\hline
\end{tabular}

Ghi chú: * có ý nghĩa thống kê tại $1 \%$.

Phương trình hồi quy:

$\mathrm{CAR}=-3.11 \mathrm{E}-17 \mathrm{SIZE}+0.911254 \mathrm{LEV}-0.560561 \mathrm{LLR}-0.070294 \mathrm{DEP}-0.002690 \mathrm{LOA}-$ $0.412457 \mathrm{LIQ}-1.395236 \mathrm{ROA}+0.140529$

\begin{tabular}{|c|c|c|c|}
\hline Biến & Dấu & Bác bỏ giả thuyết & Mức ý nghĩa \\
& - & Bác bỏ & $1 \%$ \\
\hline SIZE & - & Bác bỏ & $1 \%$ \\
\hline DEP & - & Không Bác bỏ & - \\
\hline LOA & - & Không Bác bỏ & $1 \%$ \\
\hline LLR & - & Bác bỏ & $1 \%$ \\
\hline LIQ & - & Bác bỏ & $1 \%$ \\
\hline ROA & + & Bác bỏ & \\
\hline LEV & - & . & \\
\hline
\end{tabular}

Kết quả nghiên cứu chỉ ra rằng quy mô tài sản, tính thanh khoản, khả năng sinh lời trên tổng tài sản và số tiền gửi của khách hàng có tác động âm lên hệ số an toàn vốn của ngân hàng. Trong khi đó, hệ số đòn bẩy có tác động dương lên hệ số an toàn vốn của ngân hàng. Dự phòng cho vay khó đòi, số tiền cho vay của ngân hàng tác động không có ý nghĩa lên hệ số an toàn vốn của ngân hàng.

Trong nghiên cứu này, ROA lại có tương quan nghịch chiều với CAR. Kết quả này trái ngược với nghiên cứu của Büyüksalvarcı and Abdioğlu (2011) ở các ngân hàng Thổ Nhĩ Kỳ hay Gropp và Heider (2007) khi nghiên cứu các ngân hàng ở Châu Âu. Trong khi Büyüksalvarcı and Abdioğlu thây rằng lợi nhuận ngân hàng có xu hướng giữ lại để tăng vốn và đầu tư vào tài sản vì vậy khi tăng ROA sẽ làm tăng CAR thì nghiên cứu này lại chỉ ra rằng tại Việt Nam với mức ý nghĩa $1 \%$ thì lợi nhuận trên tài sản tăng lên $1 \%$ sẽ làm cho CAR giảm 1.395236\%. Kết quả này phù hợp với nghiên cứu của Noor Mohammad Al-Sabbagh (2000) khi nghiên cứu các ngân hàng ở Jordan từ năm 1985 đển năm 1994. Kết quả nghiên cứu đã phản ánh đúng thực trạng hoạt động của các NHTMCP Việt Nam. Tốc độ tăng trưởng kinh tế cao đã làm cho tỷ suất sinh lợi trên tổng tài sản của các ngân hàng đều tăng cao, trong năm 2007, tốc độ tăng trưởng kinh tế Việt Nam đạt $8,48 \%$, đây là mức tăng trưởng cao nhất trong giai đoạn từ năm 2005-2010; ROA trung bình của các ngân 
hàng đạt mức 1,48\% cũng là mức cao nhất trong 6 năm từ 2005-2010. Một trong những nguyên nhân nữa khiến lợi nhuận của các ngân hàng tăng cao đó là chi phí dự phòng rủi ro thấp trong khi hoạt động tín dụng ngân hàng lại tiềm ẩn rất nhiều nguy cơ rủi ro trong giai đoạn này. Tăng trưởng tín dụng nóng, chất lượng tín dụng giảm sút là nguyên nhân khiến cho tỷ lệ nợ xấu của các ngân hàng tăng lên rất cao trong giai đoạn 2011-2013, điều này đe dọa đến sự an toàn trong hoạt động của ngân hàng. Khi lợi nhuận tăng thì rủi ro trong hoạt động tín dụng tăng, công thức xác định $\mathrm{CAR}$ trong giai đoạn nghiên cứu của các ngân hàng này còn đang áp dụng theo tiêu chuẩn Basel I, nên khi rủi ro tín dụng tăng cao đồng nghĩa với việc CAR giảm xuống. Hơn nữa, từ năm 2008-2010, cuộc khủng hoảng tài chính toàn cầu đã ảnh hưởng đến hoạt động của hệ thống ngân hàng nên để đảm bảo cho sự phát triển an toàn của hệ thống ngân hàng Việt Nam, NHNN đã áp dụng những quy định khắt khe hơn về mức độ an toàn vốn đối với các ngân hàng theo hướng đáp ứng các chuẩn mực quốc tế.

Bên cạnh ROA thì hệ số đòn bẩy LEV là yếu tố tác động mạnh thứ hai. Hệ số đòn bẩy của ngân hàng có mối tương quan cùng chiều với hệ số an toàn vốn của ngân hàng và có ý nghĩa thống kê tại mức ý nghĩa $1 \%$ trong mô hình. Hệ số đòn bẩy cao đồng nghĩa với việc quy mô vốn chủ sở hữu của các ngân hàng ngày một tăng cao, điều này làm cho hệ số an toàn vốn của NHTM vì thế cũng tăng cao. Điều này hoàn toàn phù hợp với thực trạng tại các NHTM đang nghiên cứu trong thời gian qua, theo nghiên cứu của tác giả tính đển thời điểm cuối năm 2016 tổng vốn chủ sở hữu của 10 ngân hàng tiên phong áp dụng Basel II chiếm gần $44 \%$ tổng vốn tự có toàn ngành ngân hàng. So với các ngân hàng còn lại trong hệ thống, vốn tự có của 10 ngân hàng này khá áp đảo, đều khoảng 600 triệu USD (MaritimeBank) đến 2,7 tỷ USD (Vietinbank). Kể từ khi gia nhập tổ chức thương mại thế giới WTO, để đảm bảo an toàn trong hoạt động cũng như tăng cường sức mạnh cạnh tranh cho các NHTM trong nước, NHNN ban hành những quy định về an toàn vốn, dưới áp lực về kế hoạch tăng vốn điều lệ tối thiểu 3000 tỷ đồng đối với các NHTMCP Việt Nam, các ngân hàng này đã đồng loạt tăng vốn chủ sở hữu với nhiều biện pháp khác nhau, kết quả làm cho hệ số an toàn vốn của các NHTM tăng lên. Do đó, có mối quan hệ cùng chiều giữa LEV và CAR. Trong nghiên cứu này thì cứ tăng $1 \%$ hệ số đòn bẩy thì các NHTM Việt Nam sẽ tăng $0.911254 \%$ CAR.

Yếu tố thứ ba tác động đến CAR của khối các NHTM này đó là tính thanh khoản LIQ. Trái ngược với kỳ vọng ban đầu là khi tính thanh khoản của ngân hàng tăng lên sẽ làm cho CAR tăng lên. Kết quả này thì hoàn toàn ngược lại là khi tính thanh khoản tăng lên sẽ làm cho CAR giảm đi với mức ý nghĩa $1 \%$.

Yếu tố tiếp theo tác động đến CAR của khối các NHTM này đó là hệ số tiền gửi của khách hàng DEP. Hệ số tiền gửi khách hàng có tác động ngược chiều lên $\mathrm{CAR}$, hệ số này có ý nghĩa thống kê tại mức $1 \%$. Theo đó, khi DEP tăng $1 \%$ thì CAR sẽ giảm $0.070294 \%$. Điều này hàm ý rằng những NHTM thu hút được lượng gửi tiền nhiều hơn sẽ có CAR ở mức thấp hơn. Kết quả đưa ra không giống với kết luận trong bài nghiên cứu thực nghiệm của Ahmet Büyükşalvarc11 and Hasan Abdioğlu khi nghiên cứu về các yếu tố tác động đến hệ số an toàn vốn ở Thổ Nhĩ Kỳ (2011). Điều này có thể giải thích ở Việt Nam trong thời gian qua, cuộc đua lãi suất huy động đỉnh điểm vào những tháng đầu năm 2012 đã đẩy lãi suất huy động tăng lên rất cao, thêm vào đó một số các ngân hàng lại sử dụng tặng thưởng lãi suất để đối phó với quy định về trần lãi suất huy động của NHNN, mặt khác một số kênh đầu tư khác như bất động sản hay chứng khoán không còn hấp dẫn với khách hàng, vì vậy lượng tiền gửi của khách hàng tăng cao nhưng hầu hết người dân chỉ chọn gửi các kỳ hạn ngắn. Tỷ lệ tiền gửi dài hạn thường chỉ chiếm trên dưới $10 \%$ trong cơ cấu tại nhiều ngân hàng. Điều này làm chi phí sử dụng vốn tăng lên và làm lợi nhuận giảm, vì thế các ngân hàng buộc phải tăng tài sản rủi ro để tìm kiếm thêm lợi nhuận và vì thế làm CAR giảm đi. Bên cạnh đó, mặc dù lượng tiền gửi của các ngân hàng này chiếm tỷ trọng lớn trong tổng lượng tiền gửi của toàn hệ thống do có ưu thế về chủ sở hữu, năng lực tài chính, mạng lưới giao dịch, thương hiệu...tuy nhiên trong giai đoạn từ năm 2014 - 2016, khối các ngân hàng này nằm trong danh mục các ngân hàng thí điểm thực hiện Basel II, vì vậy phải từng bước tiệm cận với các chuẩn mực Basel II ví dụ như cách xác định CAR điều này dẫn đến CAR của các ngân hàng này sẽ giảm xuống.

Yếu tố cuối cùng tác động đến CAR đó là quy mô tài sản của ngân hàng. Quy mô tài sản SIZE có mối tương quan âm với CAR và có ý nghĩa thống kê tại mức ý nghĩa $1 \%$ trong mô hình. Mối tương quan âm chỉ ra rằng khối các ngân hàng này càng mở rộng quy mô thì hệ số an toàn vốn càng giảm. Kết quả nghiên cứu này phù hợp với các kết quả nghiên cứu trước đây của Jim Wong, Ka-fai Choi and Tom Fong (2005) ở các ngân hàng ở Hồng Kông hay của Gropp and Heider (2007). Nghiên cứu này cho rằng ngân hàng càng lớn thì càng nắm giữ nhiều tài sản rủi ro hơn so với ngân hàng nhỏ. Tính đến cuối năm 2016 , tổng tài sản của 
10 ngân hàng này chiếm $49 \%$ toàn hệ thống. Theo xếp hạng của Tạp chí The Banker về xếp hạng 100 ngân hàng ASEAN năm 2016, Việt Nam đứng thứ hai về tốc độ tăng trưởng tổng tài sản, đạt khoảng $15,6 \%$, trong đó có Vietcombank tăng $23 \%$. Bên cạnh đó, qua số liệu thực tế về CAR ở các NHTMCP Việt Nam thì các ngân hàng có quy mô lớn như Vietinbank, Vietcombank, $\mathrm{ACB}$...thường có xu hướng kinh doanh rủi ro hơn vì thế họ chấp nhận nắm giữ nhiều tài sản rủi ro so với các ngân hàng nhỏ. Vì vậy khi quy mô tài sản ngân hàng tăng thì CAR giảm xuống.

\section{KẾT LUẬN}

Hệ số an toàn vốn là một trong những chỉ tiêu quan trọng được nhắc tới khi đánh giá hoạt động của NHTM, đây cũng là chỉ tiêu được bàn luận nhiều nhằm đưa ra cách xác định hệ số này một cách hợp lý nhất. Từ đó có thể thấy tầm quan trọng của hệ số này trong việc đánh giá hoạt động của các ngân hàng. Trong xu hướng quốc tế hoá và nền kinh tế thị trường ngày nay, các NHTM luôn phải đối mặt với hai vấn đề lớn đó là năng lực cạnh tranh và rủi ro trong hoạt động kinh doanh. Hệ số an toàn vốn là một chỉ tiêu quan trọng để đánh giá khả năng của một ngân hàng trước hai vấn đề trên. Do đó, xác định các yếu tố ảnh hưởng đến hệ số an toàn vốn tại các NHTM là một câu hỏi được đặt ra đối với các nhà quản lý ngân hàng, đặc biệt đối với các nhà quản lý ngân hàng đang thí điểm thực hiện chuẩn mực Basel II.

Kết quả hồi quy cho thấy, hệ số an toàn vốn có thể được giải thích tốt bởi các yếu tố cơ bản của các NHTM. Quy mô ngân hàng được đại diện bằng biến tổng tài sản có tương quan ngược chiều với $\mathrm{CAR}$, điều này hàm ý rằng các ngân hàng Việt Nam càng mở rộng quy mô thì hệ số an toàn vốn càng giảm. Ngân hàng càng lớn thì càng nắm giữ nhiều tài sản rủi ro hơn so với ngân hàng nhỏ. Số tiền gửi của khách hàng, tính thanh khoản của ngân hàng và lợi nhuận của ngân hàng được đại diện bằng biến khả năng sinh lời trên tổng tài sản (ROA) có tương quan ngược chiều với CAR. Trong khi đó, hệ số đòn bẩy có tác động dương lên hệ số an toàn vốn của ngân hàng. Hệ số đòn bẩy cao đồng nghĩa với việc quy mô vốn chủ sở hữu của các ngân hàng ngày một tăng cao, điều này làm cho hệ số an toàn vốn của NHTM vì thế cũng tăng cao.

Với những kết quả đạt được, nghiên cứu này đã bước đầu cung cấp cho các nhà quản lý ngân hàng những yếu tố ảnh hưởng đến hệ số an toàn vốn tại các NHTM, từ đó có thể dựa vào sự vận dụng lý thuyết, kết quả thực nghiệm và tình hình thực tế để đưa ra những chính sách phù hợp nhất. Những hàm ý nghiên cứu cho thấy để nâng cao hệ số an toàn vốn trên cơ sở đảm bảo an toàn trong hoạt động của các NHTM, các ngân hàng có thể tăng vốn chủ sở hữu trên cơ sở phù hợp với tốc độ tăng tổng tài sản và xây dựng chiến lược tăng vốn đi kèm với sử dụng vốn hợp lý để đảm bảo sự phát triển vốn bền vững; xây dựng một chính sách lãi suất tiền gửi hợp lý và thực hiện dự trữ tiền mặt và các khoản tương đương tiền phù hợp để tăng nguồn cho vay có chọn lọc, hạn chế cho vay những khoản vay có mức độ rủi ro cao, cần cơ cấu lại cho vay vào các lĩnh vực nhạy cảm và rủi ro nhiều như chứng khoán, bất động sản và tiêu dùng...quan tâm đến chất lượng khoản vay không chạy theo doanh số cho vay. Ngoài ra, các ngân hàng cần thực hiện các biện pháp gia tăng lợi nhuận nằm trong phạm vi rủi ro cho phép của ngân hàng, chú trọng các khoản thu nhập ngoài lãi, có kế hoạch tăng vốn chủ hữu qua các kênh như bán cổ phần cho các nhà đầu tư chiến lược nước ngoài, vừa thực hiện được mục tiêu tăng vốn, vừa tận dụng các ưu thế của nhà đầu tư nước ngoài như công nghệ, quy trình, sản phẩm, cơ chế quản lý rủi ro và tính minh bạch trong kinh doanh... ở tầm "quốc tế".

\section{TÀI LIÊUU THAM KHẢO}

1. Báo cáo thường niên, báo cáo tài chính của 10 NHTM Việt Nam từ năm 2007 - 2016 bao gồm: Vietcombank, BIDV, VietinBank, Techcombank, ACB, VPBank, MBB, MaritimeBank, Sacombank và VIB

2. Báo cáo thường niên của Ngân hàng Nhà nước từ năm $2007-2016$

3. Ngân hàng Nhà nước Việt Nam, 2014. Công văn số 1601/NHNN-TTGSNH ngày 17/3/2014 lựa chọn 10 ngân hàng trong nước thi điểm triển khai Basel II.

4. Ngân hàng Nhà nước Việt Nam, 2011. Định huoóng và giải pháp cơ cấu lại hệ thống ngân hàng Việt Nam giai đoạn 2011 - 2015.

5. Ngân hàng Nhà nước Việt Nam, 2006. Đề án phát triển ngành ngân hàng đến 2012 và định huớng đến 2020.

6. Ngân hàng Nhà nước Việt Nam, 2006. Nghị định 141/2006/NĐ-CP ngày 22/11/2006 ban hành danh mục vốn pháp định của các tổ chức tín dụng.

7. Ngân hàng Nhà nước Việt Nam, 2010. Thông tu 13/2010/TT-NHNN ngày 20/5/2010 quy định về tỷ lệ đảm bào an toàn hoạt động của tổ chức tín dụng.

8. Ngân hàng Nhà nước Việt Nam, 2010. Thông tu 19/2010/TT-NHNN ngày 27/9/2010 sủa đổi, bổ sung một số 
điều của thông tu 13/2010/TT-NHNN ngày 20/5/2010 quy định về tỷ lệ đảm bào an toàn hoạt động của tổ chưc tín dung.

9. Ngân hàng Nhà nước Việt Nam, 2010. Thông tu 02/2013/TT-NHNN ngày 21/01/2013 về phân loại nợ và trích lập dụ phòng rủi ro tín dụng.

10. Ngân hàng Nhà nước Việt Nam, 2016. Thông tu 41/2016/TT-NHNN ngày 30/12/2016 quy định về tỷ lệ an toàn vốn đối với ngân hàng và chi nhánh ngân hàng nước ngoài.

11. Nguyễn Minh Kiều, 2011. Nghiệp vu ngân hàng thuơng mại. Nhà xuất bản thống kê.

12. Nguyễn Thị Mùi, 2013. Hệ thống ngân hàng Việt Nam sau sáu năm hội nhập. Tạp chí ngân hàng, số 14, tháng $7 / 2013$.

13. Phạm Hữu Hồng Thái, 2013. Các yếu tố quyết định hệ số an toàn vốn của hệ thống ngân hàng thuoong mại Việt Nam 2006 - 2010. Nghiên cứu kinh tế, số 4, trang 30 - 36.

14. Tôn Thanh Tâm, 2012. Khó khăn và thách thức của hệ thống ngân hàng thuơng mại Việt Nam trong việc vận dụng các quy định về tỷ lệ an toàn vốn theo tinh thần Hiệp uớc Basel III. Tạp chí ngân hàng, số 16, tháng $8 / 2012$

15. Trầm Thị Xuân Hương và Hoàng Thị Minh Ngọc, 2012. Nghiệp vu ngân hàng thuoong maị. Nhà xuất bản Kinh tế tp. Hồ Chí Minh.

16. Trần Huy Hoàng, 2011. Quản trị ngân hàng thuơng mại. Nhà xuất bản Lao động Xã hội.

Danh mục tài liệu tiếng Anh

17. Ahmet Büyükşalvarcı and Hasan Abdioğlu, 2011. Determinants of capital adequacy ratio in Turkish Banks: A panel data analysis. African Journal of Business Management Vol.5 (27), pp. 11199-11209.

18. Angbazo, L. (1997). Commercial bank net interest margins, default risk, interest-rate risk, and offbalance sheet banking. Journal of Banking and Finance, 21(1), 55-87.

19. Asarkaya Yakup and Serkan Ozcan, S. (2007). Determinants of capital structure in financial institutions: The case of Turkey. Journal of BRSA and Financial Markets, 2007, Vol 1, 1, 91-109.

20. Arellano, M., and S. Bond. 1991. Some tests of specification for panel data: Monte Carlo evidence and an application to employment equations. Review of Economic Studies 58: 277-297

21. Farah Margaretha and Diana Setiyaningrum, 2011, Pengaruh Resiko, Kualitas Manajemen, Ukuran dan Likuiditas Bank terhadap Capital Adequacy Ratio Bank-Bank yang Terdaftar di Bursa Efek Indonesia. Jurnal akuntansi dan keuangan, Vol. 13, No. 1, Mei 2011: 47-56.

22. Gropp and Heider, 2007, The determinants of Bank capital Structure. Working PaPer Series No 1096. September 2009.

23. Hausman, J.A. and Taylor W.E. (1981). Panel Data and Unobservable Individual Effects, Econometrica, Vol 49, 6, 377-1398.

24. Ijaz Hussain Bokhari, Syed Muhamad Ali, 2011, Determinants of Capital Adequacy Ratio in banking sector: An empirical analysis from Pakistan. Acadamy of Contemporary research Journal.

25. Jim Wong, Ka-fai Choi and Tom Fong, 2005, The cost efficiency of commercial banks in Hong Kong. Hong Kong Monetary Authority

26. Li Yuanjuan and Xiao Shishun, 2012, Effectiveness of China's Commercial Banks' Capital Adequacy Ratio Regulation A Case Study of The Listed Banks. Interdisciplinary journal of contemporary research in business, Vol 4, 2012.

27. Mohammed T. Abusharba, Iwan Triyuwono, Munawar Ismail and Aulia F. Rahman, 2013. Determinants of Capital Adequacy Ratio (CAR) in Indonesian Islamic Commercial Banks. Global Review of Accounting and Finance Vol. 4. No. 1. March 2013. Pp. 159 - 170.

28. Ozili, P, 2015. Determinants of bank profitability and Basel capital regulation: empirical evidence from Nigeria. Munich Personal RePEc Archive, Paper No. 61069.

29. Raharjo, P. G., Hakim, D. B., Manurung, A. H. and Maulana, T. N. A., 2014. Determinants of capital ratio: a panel data analysis on state-owned banks in Indonesia. Buletin Ekonomi Moneter Jan Perbankan, No 16 (4), 395-414 
NGHIÊN CƯU CÁC YÊU TỐ ẢNH HƯỞNG ĐÊN HÊ SỐ AN TOÀN VỐN TẠI CÁC NGÂN HÀNG 127 THƯƠNG MẠI VIẸTT NAM ĐƯợC NGÂN HÀNG NHÀ NƯỚC CHİ ĐỊNH THÍ ĐIỂM THỰC HIỆN BASEL II

\section{PHỤ LỤC}

PHỤ LỤC 1: 10 Ngân hàng thương mại cổ phần Việt Nam được dùng để phân tích và đánh giá từ 2007- 2016

\begin{tabular}{|l|l|l|}
\hline STT & Ngân hàng & Mã ngân hàng \\
\hline 1 & Ngân hàng TMCP Công Thương & CTG \\
\hline 2 & Ngân hàng TMCP Ngoại Thương & VCB \\
\hline 3 & Ngân hàng TMCP Á Châu & ACB \\
\hline 4 & Ngân hàng TMCP Đầu tư và Phát triển & BIDV \\
\hline 5 & Ngân hàng TMCP Sài Gòn thương tín & STB \\
\hline 6 & Ngân hàng TMCP Quân đội & MBB \\
\hline 7 & Ngân hàng TMCP Hàng hải & Maritimebank \\
\hline 8 & Ngân hàng TMCP Việt Nam Thịnh vượng & Vpbank \\
\hline 9 & Ngân hàng TMCP Quốc tế & VIB \\
\hline 10 & Ngân hàng TMCP Kỹ Thương & Techcombank \\
\hline
\end{tabular}

\section{PHỤ LỤC 2: KẾT QUẢ THỐNG KÊ MÔ TẢ CÁC BIẾN}

\begin{tabular}{r|rrrrr} 
Variable & Obs & Mean & Std. Dev. & Min & Max \\
\hline car & 100 & .125445 & .0361629 & .0667 & .2665 \\
size & 100 & $2.32 e+14$ & $2.13 e+14$ & $1.76 e+13$ & $1.01 e+15$ \\
lev & 100 & .078102 & .0224539 & .0065402 & .1468588 \\
llr & 100 & .0117386 & .0072398 & .0001584 & .031859 \\
dep & 100 & .636 & .126339 & .0600289 & .8921708 \\
\hline loa & 100 & .5134547 & .1273566 & .2200516 & .7311747 \\
liq & 100 & .0185134 & .0206861 & .0049161 & .1235943 \\
roa & 100 & .0127133 & .0058583 & .0004686 & .0273415
\end{tabular}

PHỤ LỤC 3: MA TRẬN HIỆP PHƯƠNG SAI

\begin{tabular}{|c|c|c|c|c|c|c|c|c|}
\hline & car & size & lev & $\ln$ & dep & loa & liq & roa \\
\hline car & 1.0000 & & & & & & & \\
\hline size & -0.3942 & 1.0000 & & & & & & \\
\hline lev & 0.5892 & -0.3882 & 1.0000 & & & & & \\
\hline $\ln$ & 0.0339 & 0.0553 & 0.1348 & 1.0000 & & & & \\
\hline dep & -0.3081 & 0.2420 & -0.0316 & 0.0588 & 1.0000 & & & \\
\hline loa & -0.3338 & 0.5356 & -0.1480 & -0.1628 & 0.5358 & 1.0000 & & \\
\hline liq & -0.0676 & -0.2226 & 0.2098 & -0.3691 & -0.0229 & -0.0751 & 1.0000 & \\
\hline roa & -0.1772 & -0.1716 & 0.0123 & -0.2380 & -0.0718 & -0.0582 & 0.3258 & 1.0000 \\
\hline
\end{tabular}


128 NGHIÊN CÚU CÁC YÊU TỐ ẢNH HƯỞNG ĐẾN HÊ SỐ AN TOÀN VỐN TẠI CÁC NGÂN HÀNG THƯƠNG MẠI VIẸTT NAM ĐƯợC NGÂN HÀNG NHÀ NƯỚC CHİ ĐỊNH THÍ ĐIỀM THỰC HIỆN BASEL II

\section{PHỤ LỤC 4: KIỂM ĐỊNH HIẸN TƯợNG PHƯƠNG SAI THAY ĐỔI}

Breusch-Pagan / Cook-Weisberg test for heteroskedasticity

Ho: Constant variance

Variables: fitted values of car

$\begin{array}{ll}\operatorname{chi2}(1) & =12.61 \\ \text { Prob }>\text { chi2 } & =0.0004\end{array}$

\section{PHỤ LỤC 5: KIỂM ĐỊNH HIẸN TƯợNG TỬ TƯƠNG QUAN}

Wooldridge test for autocorrelation in panel data

HO: no first order autocorrelation

$$
\begin{aligned}
\mathrm{F}(1, \quad 9) & =13.066 \\
\text { Prob }>\mathrm{F} & =0.0056
\end{aligned}
$$

\section{PHỤ LỤC 6: KÊTT QUẢ HỒI QUY THEO FGLS}

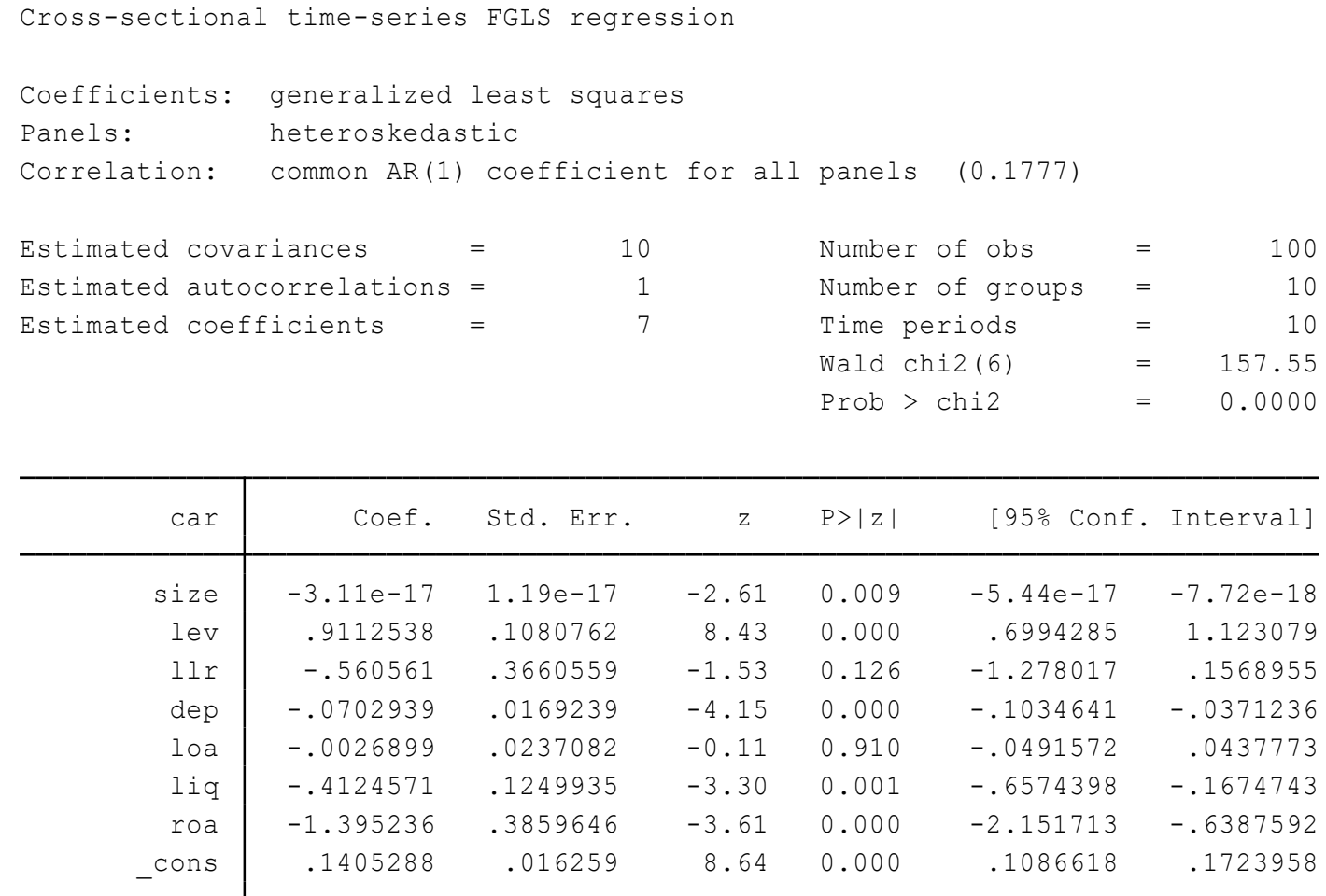

Ngày nhận bài: 05/01/2018

Ngày chấp nhận đăng: 15/08/2018 